\title{
Flood Action Programs (PAPI): rating the flood's collective vulnerability through the implementation of an integrated public policy tool
}

\author{
Flora Guillier ${ }^{1,2, a}$ \\ ${ }^{1}$ Mission Risques Naturels, 75431 Paris cedex 9, France \\ ${ }^{2}$ Lab'urba, Université-Paris-Est, Cité Descartes, 77454 Marne-la-Vallée Cedex 2, France
}

\begin{abstract}
Assessment of vulnerability to flooding has been widely investigated by researchers, policy makers and practitioners. The research project initiated between the French insurance dedicated association to natural risks, MRN, and the urban planning lab Lab'urba, proposes to address this question from "action". By making the assumption that territorial vulnerability depends on the collective measures implemented by communities, this research project aims to experiment a national rating method of the territorial preventive effort. To investigate collective prevention, Flood Action Programmes (PAPI) have been identified as the one bottom-up public policy instrument that mobilizes all the prevention actions' levers. The constitution of a PAPI's actions' database, homogenized through a codification process, provides 82 codes reflecting the diversity of actions. To score PAPI, we need beforehand to rate the codes regarding their impact in terms of vulnerability reduction. The codes rating system, produced in collaboration with experts, is based on AHP-ANP models. The resulting national PAPI's scoring will be confronted with different local case studies, e.g. in the context of coastal floods, river floods..., in order to appreciate to what extent the national rating system is adapted to local scale and reflect the territorial efforts to reduce vulnerability to flooding.
\end{abstract}

\section{Introduction}

\subsection{General context}

Assessment of vulnerability to flooding has been recently widely investigated by researchers, policy makers and practitioners [1-4]. This increasing interest follows decades of projects focused on hazard knowledge improvement, especially in geography and civil engineering techniques fields. In France, this hazardoriented approach has dominated flood risk management (FRM) strategies until the mid-to-late $20^{\text {th }}$ century [5-6].

The recognition of the limits of such an approach as mentioned by Hewitt [7] and White [8], and the growing awareness of flood risk anthropic and societal dimensions, in particular regarding the high urbanization in flood-prone areas, have put vulnerability in the spotlight [5,9]. Natural risks thus result from the complex interaction of hazard and vulnerability [2, 10-13]. Vulnerability is thus defined in relation to hazard. Furthermore, the complexity of their interaction has participated in the diversity of vulnerability's definitions.

Literature review outlines vulnerability's high polysemy according to the addressed disciplines or targeted applications [2, 4, 5, 9, 13-16]. We don't intend to present a comprehensive nor exhaustive review of the diversity of definitions, which has already been the object of numerous works [2, 12, 17].

In parallel, other close concepts became of central interest such as adaptive capacity, coping capacity, resilience which ask for the identification and definitions of their linkages with vulnerability [15, 18-20].

If the question of "vulnerability to what?" is answered in this article as we focus on floods, one of the remaining part of vulnerability definition we have to tackle with is the question of scale. Indeed, one could distinguish the vulnerability at the individual scale, considering people or building for example, from collective vulnerability, which consider a group of individuals, consequently at a larger scale, such as a territory, which also calls for definitions [20-21].

The definition and clarification of the different concepts and terms appears a significant and core issue as far as vulnerability and its assessment are concerned.

\subsection{A specific Public-Private-Partnership framework}

This research project aims to answer the question of the assessment of vulnerability to flooding in a specific context. It relies on a collaborative framework between the urban planning lab, Lab'urba and the Association of French Insurance Undertakings for Natural Risk

\footnotetext{
a Corresponding author: flora.guillier@mrn.asso.fr
} 
Knowledge and Reduction, MRN, which was created in 2000 by the French Trade associations.

Indeed, France established a national risk transfer scheme based on a public private partnership (PPP) between insurance industry and the State as its guarantor [22]. This compensation scheme, since the Act of July 13, 1982, relies on national solidarity so that all citizens who enter into a contract of insurance covering damage to property (home, car, business) pays a compulsory fixed rate additional-premium with this rate fixed by the State. The compensation tackles with the direct damages relative to the effects of major disasters (floods, droughts, earthquakes ...).

Furthermore, flood damages account for near half the compensation's charges with regards to this system - 400 Million EUR as an average annual charge- [23]. Damaging climatic events are intended to increase in intensity due to climate change $[24,25]$. The recent study realized by the French Insurance Association (AFA) expects this cost to double by 2040 [23]. Therefore, MRN stands for the French insurers' growing concern and involvement about damaging climatic events, especially flood risk.

Part of MRN's mission consists in the development of specific tools for professional purposes to assess flood risk, particularly by reflecting vulnerability. Thus, we shall reinvestigate the question of vulnerability definition in an operational way. To that end, we will first analyze how to bridge the different academic approaches with MRN's mission.

\section{Conceptual framework}

In this section, we aim to articulate the definitions of vulnerability as well as similar concepts on the one hand, and the professional context which is part of this research project on the other hand. To this end, we will provide a brief overview of main approaches of vulnerability in the respective biophysical and social realms $[4,5,26]$.

\subsection{Biophysical vulnerability}

The first category of vulnerability's definition is derived from the hazard paradigm [5]. Risk is here considered as the result of (1) hazard characterized by a probability (frequency, intensity) and (2) vulnerability as the potential impact of this hazard. Vulnerability is therefore mainly characterized by damaging propensity $[11,17,26]$. This definition was chosen by French Ministry in charge of environment, which considers vulnerability as the expression and the assessment of foreseeable negative consequences of flood events [11]. Considering vulnerability as damaging propensity corresponds to the common approach within the fields of natural scientists, engineers, disasters managers ... [27]. It particularly makes sense within insurance industry; In this perspective, compensated damages related to floods are proxies that reveal the pre-existing vulnerability with regards to direct material damages [17].

The physical part of vulnerability focuses on the assessment of damaging propensity by the use of empirical damage functions: they establish correlations between a damaging degree, i.e. an economic impact, and hazard's intensity $[11,16]$. Vulnerability is here assessed by summing all potential damages.

Damaging functions have however revealed some limitations. Indeed, the link between hazard's characteristics such as height, speed... and damages is not obvious [28,29].

All scholarships recognize that vulnerability shall not be restricted to direct damages' measure but has to identify and assess factors that contribute to it $[16,30]$. While pursuing the biophysical approach, two main factors were pointed out: exposure and sensitivity [5, 15, 20]. Exposure can refer to the elements' geographic location [14, 31]. The concept of sensitivity was introduced to consider that two equally exposed elements might be differently affected according to their sensitivity $[5,31,32]$. Thus, biophysical approach is determined in relation with hazard (nature and characteristics) and takes account of elements' exposure and sensitivity with regards to this hazard $[5,14]$.

In the same perspective, MRN, on behalf of its members, monitors and promotes public data on hazard zoning and assets exposure through an extranet platform of geo-services [33]. Elements' sensitivity appears less operational as far as assessment is concerned. Furthermore, such an approach appears pessimistic as it doesn't take account of the capacity of these elements, which are part of a system to react with regards to this existing flood risk.

Vulnerability defined as damaging propensity is meaningful in our specific context. Nevertheless, the biophysical factors approaches appear more or less operational and lack the inclusion of some variables.

\subsection{Social vulnerability}

In parallel to biophysical vulnerability, American social sciences have developed the concept of social vulnerability. This approach considers (1) a hazard as a stress or perturbation that affects (2) a system characterized by its response [5].

This response capacity has been investigated, on the one hand, through the question of social factors contributing to vulnerability [10]. In particular, research works identified a wide range of root causes to biophysical vulnerability such as gender, age, institutional, economical factors ... [10, 34].

If the social root causes approach may not be operational in our current project, social vulnerability considers on the other hand the concept of response. It constitutes the system's coping capacity, also labeled capacity of response, adaptive capacity or resilience [15]. In this perspective, social vulnerability investigates the "active" capacity of the system so that it expresses "the characteristics of a person or group in terms of their capacity to anticipate, cope with, resist, and recover from the impact of a natural hazard" [27].

Conceptual frameworks surrounding resilience, adaptive capacity... vary according to the authors. For example, some authors consider resilience as the flip side 
of vulnerability [17]. Here, we adopt the approach developed in Gallopin that considers resilience and adaptive capacity as components of vulnerability [15]. With regards to the many polysemous concepts that refers to it, we choose within the current project, the term of flood risk coping capacity defined, as proposed by the United Nations (UN), as "a combination of all strengths and resources available within a community or organization that can reduce the level of risk, or the effects of a disaster" [35].

The operational side of this social approach lays in the manifestations of this risk coping capacity, as stated in the UN definition. Thus, vulnerability, considered at a system's scale, becomes a cornerstone towards vulnerability and consequently risk reduction [2, 20, 27].

In this perspective, social vulnerability stands for another central issue to take in account. Within our specific PPP context, this approach considers the ability of the system to conduct operational preventive actions.

The biophysical and social approaches are, in that sense, complementary. Many authors thus define vulnerability as a combination of exposure, sensitivity as well as risk coping capacity [2,15,20,32].

\subsection{Characterizing vulnerability to flooding in the current project}

The brief literacy review permits us to highlight that both biophysical and social approaches may be meaningful with regards to our specific context. The aim of it was more to see how and to what extent we can link the different approaches in the operational framework of this research project than to propose a new definition and conceptual framework.

We therefore use the definition of vulnerability as the damaging propensity. With regards to the national compensation scheme, we will focus on direct material damages. Furthermore, vulnerability to flooding is first function of exposure and sensitivity. But exposure and sensitivity are also function on the risk coping capacity, as illustrated within the following "equations":

$$
\begin{aligned}
\text { Vulnerability } & =\mathrm{f} 1 \text { (Exposure, Sensitivity) } \\
& =\mathrm{f} 2(\text { Risk coping capacity }) \\
& \approx \text { Direct material damages }
\end{aligned}
$$

This approach brings a little difference from authors that considers vulnerability's factors on the same level. Here, we distinguish contributing factors, that corresponds to the first level's factors explaining direct damages and a second level which may impact the contributing factors and the overall vulnerability.

In this perspective, preventive actions are operational declinations of risk coping capacity which induce an impact on exposure and sensitivity. Assessing risk coping capacity through actions permits us to consider a dynamic approach of vulnerability. Within our PPP framework and particularly within the context of insurance undertakings, prevention actions implemented at the individual scale can be appreciated through their direct relations with insured people. However, there is still a great challenge regarding the impact on systems of prevention actions implemented at a collective scale [15]. Thus we question how to integrate and assess flood risk collective coping capacity. To that end, we shall first go further in the definition of risk coping capacity and identify its operational declinations in actions.

In terms of FRM, the French national policy emphasizes seven collective levers of action relative to prevention: (i) hazard and assets' knowledge, (ii) watercourse monitoring, forecasting, vigilance and warning, (iii) education and preventive information, (iv) control of urbanization and built environment, (v) reduction of the vulnerability (mitigation), (vi) defence including all measures related to hydraulic infrastructures and (vii) emergency preparedness.

In parallel, other countries as well as research works, have produced action's frameworks, e.g. the Scottish "4A's" action framework which refers to awareness, alleviation, avoidance and assistance [36], the European STAR-FLOOD project which identifies five main strategies through prevention, mitigation, defence, preparation and recovery [37], the work of Steinführer et al. [38] about social vulnerability and resilience, which emphasizes local knowledge, awareness, mitigation and adaptation, flood coping, recovery and reconstruction.

With regards to these different typologies, we consider six main collective levers of action:

-Risk knowledge

-Risk awareness through education and preventive information

-Risk adaptation including both urbanization controlling and mitigation

-Resistance to floods which includes hazard-oriented measures

-Flood's anticipation which means watercourse monitoring, forecasting and vigilance

- Reaction to floods, often referred to as flood's coping capacity or crisis management

Recovery and reconstruction aren't included in our study; with regards to vulnerability as damaging propensity, post-crisis measures have much less or no impact in reducing direct damages. Furthermore, these capacities are mainly related to compensations within the French natural disaster compensation scheme [39]. But compensations are considered here as proxies for vulnerability.

\section{Assessing flood risk collective coping capacity through public action}

The conceptual framework permits us to identify flood risk coping capacity, at the collective scale, as a key variable with regards to vulnerability assessment. The different FRM frameworks have highlighted different levers of actions, that we synthetize under six main categories. We shall here investigate the question of how to assess the collective risk coping capacity with regards to these six levers. Furthermore, as we question the 


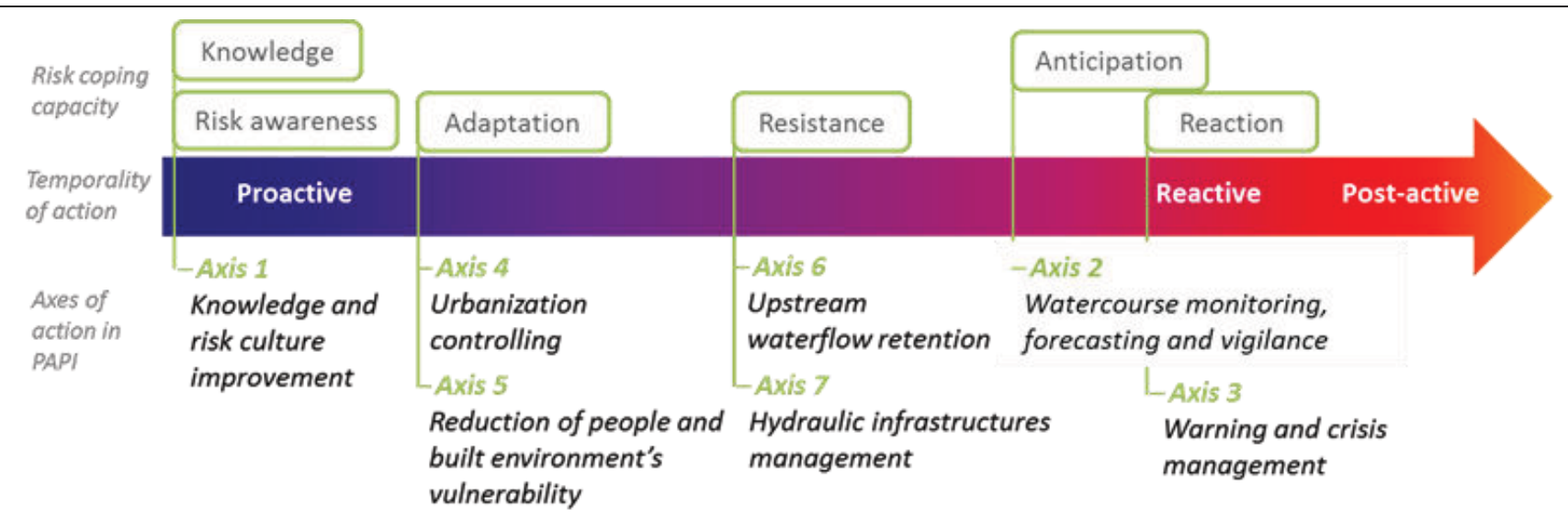

Figure 1. Risk coping capacity and actions in PAPI: a relevant match

impact of the implemented actions on systems, it questions the relevant scale to take in account regarding actions and the affected system.

\subsection{The central role of public actions in FRM}

Collective prevention calls for actions besides the individual scale, or, in other words, refers to actions that benefit a group of individuals. As a covariant risk that can affect an entire population, flood risk is considered a public problem of general interest which requires state intervention [40]. Thus, public policies and public actions stand for collective capacities to face public problems which reflect vulnerability [21]. This is consistent with the approach of Turner et al. [32], which associates the concept of coping, adjustment and adaptation responses, considered as our risk coping capacity, with the example of policies and programs. Indeed, risk coping capacity may be considered as something to enhance within a policy objective [27]. Mény and Thoenig outlines that public policies be analysed through their concrete expression in governmental action programme [41].

In France, FRM strategies have significantly evolved during the 20th century, in particular in the past thirty years, leading to a diversification and multiplication of public policy tools [40]. Two parallel processes participate in these changes: on the one hand, flood risk becomes a policy object per se $[6,11]$. It's accompanied with new specific public policy instruments that tend to integrate the plural sectors that address flood risk - land planning and urbanism, water, civil security...-. On the other hand, the decentralization process initiated in the 80 's has handed increasing responsibilities over to local authorities and enhanced territorialized instruments, including in the field of natural risks [39].

As far as bottom-up and territorialized initiatives are concerned, risk basins have been stated as the relevant FRM scale within the legal framework: laws were enacted in 1964 and 1992, and have been reaffirmed at a European level by the Water Framework Directive (2000/60/CE) and the Floods Directive (2007/60/EC). Risk basin scale is consistent with the concept of "problemsheds" [42]. Indeed, risk basins are defined as a homogenous geographical unit that is subject to the same natural phenomenon: that is, one that shares the same risk
[44]. For example, watershed basins are the risk basin scale when river floods are being tackled, as they include the whole territory across which watercourses and runoffs plays a role in the flooding phenomenon.

Consequently, flood risk collective coping capacity has to be handled at the risk basin scale. We shall identify a relevant public policy instrument with regards to the six main levers we previously defined.

\subsection{Action Programmes for Flood Prevention (PAPI)}

Throughout the multitude of existing instruments, Action Programmes for Flood Prevention, which are commonly known as PAPIs, reflect this tendency to support local governance with a view to the creation of transversal and integrated FRM [39]. As a bottom-up initiative, its purpose is to mobilize cross-scale and crosssectoral stakeholders to address all aspects of flood risk and vulnerability issue. PAPI consider the risk basin scale. It stands for the only public policy tool, specific to flood risk, which considers all the levers of action of the risk coping capacity, as illustrated in Figure 2.

Implemented on 112 risk basins that represent more than $40 \%$ of France area, this work is based upon the assumption that PAPI offer an adequate window on the collective preventive actions that are implemented on territories and that their evaluation can be used to assess the prevention effort.

\subsection{Material: constitution of a PAPI's actions database}

In order to assess flood risk collective coping capacity throughout PAPI, the first step was to constitute an operational database gathering all the actions implemented in each PAPI. As no national database currently exists upon financial budget neither intended actions in PAPI, the database was filled in from the analysis of PAPI entire application forms. To score PAPI according to the same analysis grid, actions were homogenized through a codification process. The codification's objective was to represent the diversity of possible actions with reference to their role in the reduction of vulnerability at the collective scale. The 
code's identification was thus based on, amongst others, their contribution regarding the six main levers of action, their redundancy in different programs, their recognition in other frameworks such as subsidized action's categories by national prevention fund (FPRNM) or research works [44], the target of the action...

The codification process led to the creation of 82 codes, which can be associated with one main lever of actions, as illustrated in the Table 1 . We consider that one code may contribute to more than one lever, e.g. the realization of crisis exercise that helps improving the crisis management as well as risk awareness by associating people to the exercise.

\begin{tabular}{lccl}
\hline $\begin{array}{c}\text { Lever of } \\
\text { action }\end{array}$ & $\begin{array}{c}\text { Number } \\
\text { of codes }\end{array}$ & \multicolumn{1}{c}{ Subcategories } \\
\hline Knowledge & 21 & $\begin{array}{l}\text { Risk knowledge studies and also } \\
\text { prior studies to action }\end{array}$ \\
\hline $\begin{array}{l}\text { Risk } \\
\text { awareness }\end{array}$ & 13 & $\begin{array}{l}\text { Outreach projects according to their } \\
\text { targets and material }\end{array}$ \\
\hline Adaptation & 17 & $\begin{array}{l}\text { Planning strategies and planning } \\
\text { plans, Mitigation, Relocation }\end{array}$ \\
\hline Resistance & 16 & $\begin{array}{l}\text { Flood control infrastructures, } \\
\text { Floodplain management }\end{array}$ \\
\hline Anticipation & 3 & $\begin{array}{l}\text { Watercourse monitoring, } \\
\text { forecasting }\end{array}$ \\
\hline Reaction & 12 & $\begin{array}{l}\text { Warning system, crisis } \\
\text { management, post-crisis } \\
\text { organization }\end{array}$ \\
\hline
\end{tabular}

Table 1. Number of codes with reference to the main lever of actions and general subcategories

Comparing actions and codes of action, the number of actions in PAPI varies from 2 to 97 with an average of 24 actions. Considering the number of codes, the range varies from 1 to 42 with an average of 21 . The codification tends to reduce the number of actions and the dispersion of data; this is explained by the fact that (i) programs sometimes implement several times the same action but it is counted only once under the codification process and (ii) some programs detail their actions under several sheet actions whereas some others mention a global sheet action.

In this research work, we assume that PAPI offer an adequate window on flood risk collective coping capacity. In parallel, through PAPI's scoring, we intend to highlight differences between PAPIs, according to the local effort and specificities. The analysis of the codified action database provides a first glance at the differences between risk basin scales with regards to the preventive effort.

\section{First analysis of the difference in risk coping capacities according to risk basins}

From the analysis of the action's database, and the result of the codification process, we here investigate the question of the adaptation of PAPIs to local specificities. In this perspective, we question the diversity of PAPI and thus the diversity of risk coping capacities. We will also point out the ability of our database to point out differences in local risk coping capacity.

\subsection{Differences between PAPls relating to studies or " heavy » works}

PAPI public policy instrument considers different types of programmes; on the hand what is called "complete" PAPI have to deal, through their actions, with all the seven axis that we presented in Figure 2 in Section 3.2 , including "heavy" works. On the other hand, while local knowledge may not be considered to be adequate for developing a complete programme, local authorities can make the decision to develop an "intended" PAPI: that is, to create a small study-based programme so as to gather together enough knowledge over the course of one or two years to prepare a complete programme. "Intended" PAPIs have been launched in 33 risk basins to date, and seven of them have already been followed up with a "complete" PAPI.

The result of the codification process takes account of these two categories, as illustrated in Figure 2. Indeed, "complete" PAPI implement in average 27 type of actions while "intended" PAPIs launch less than 15 types of actions in average. As a consequence, our database makes clear evidence about the higher number of actions in complete PAPIs. However, another interesting point in that the number of codes may overlap: the minimum number of implemented codes among "complete" PAPIs is 10 while an intended PAPI reached 26 types of actions. Consequently, there is a great distribution of data.

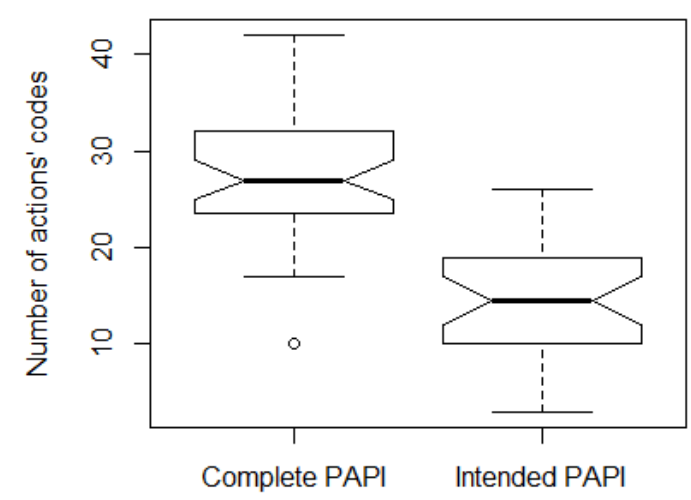

Figure 2. Distribution of the number of codes according to PAPIs' types

\subsection{Differences between PAPIs according to local specificities}

Further to the adaptation of PAPIs to local knowledge, we may point out the differences in risk coping capacities throughout PAPIs by the analysis of budget allocations. Such an analysis tends to show their diversity, as illustrated in Figure 3: in the north of France, the selected actions have enhanced resistance through upstream flood retention. This strategic choice can be linked to the topography of the risk basins and to land use - relatively gentle slopes and more rural areas. 


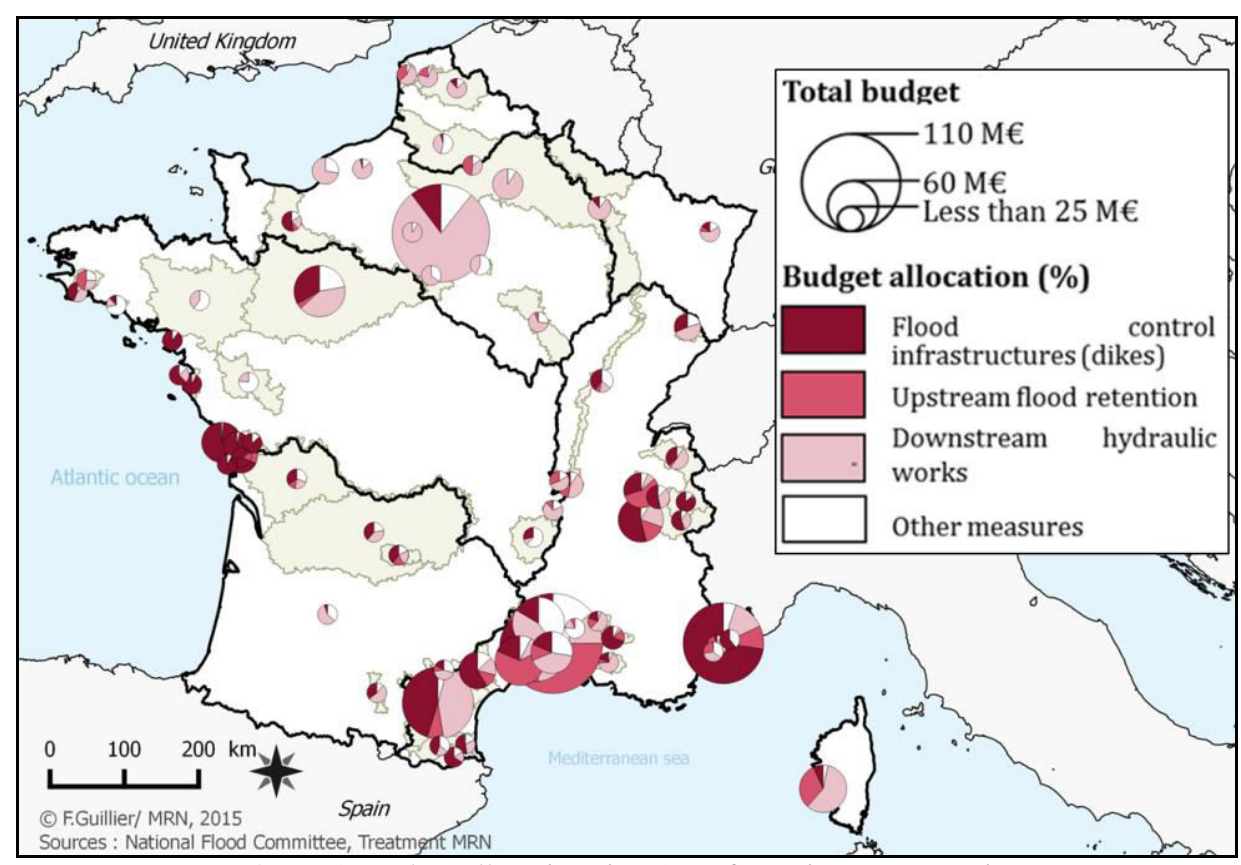

Figure 3. Budget allocations in PAPIs for resistance strategies

This is different from the situation in typical coastal risk basins, especially in the Atlantic coastal areas, where the emphasis is also on resistance but focused on dike building and reinforcement.

This economic analysis on the codified database also demonstrates that most of the budget is allocated to resistance. Indeed, more than $80 \%$ of PAPis' budget is dedicated to resistance in average. However, this doesn't mean that resistance is more effective. It only tends to show it's the most expensive lever. Furthermore, risk basins which invest more money in PAPIs does not mean that their ability to cope with risk is, obviously, more important.

The economic approach, while interesting, in particular in terms of efficiency, may not reflect the impact of actions in terms of risk coping capacity and their impact of vulnerability. Furthermore, the constituted database doesn't provide economic information for all actions. This lends support for the use of the typology of actions derived from the codes, to assess risk coping capacity. We shall thus investigate the question of codes assessment in terms of effectiveness with regards to risk coping capacity.

\section{Assessing collective reduction of vulnerability through expert valuation}

The identification of PAPI as a relevant public policy instrument to assess flood risk collective coping capacity led to the constitution of 82 codes of action reflecting the diversity of actions within the six main levers of actions. We shall now investigate the question of codes assessment in terms of effectiveness with regards to risk coping capacity.

\subsection{The need for expert valuation}

Even though the quantitative effect on damages would be the most relevant approach to rate the 82 codes, this cannot be implemented. In fact, such an assessment would imply a wide range of "ideal data" such as we would have loss data relative to two similar flood events occurring in the same place with one prevention measure implemented between the two events. Such an experimental design is quite rare. Furthermore, the current availability of loss data is limited as well as the number of well-documented quantitative feedbacks [29]. The choice was made, as a consequence, to base this approach on an expert valuation, as this was the case for the American "Community Rating System" (CRS).

CRS is a voluntary incentive program created in 1990 within the National Flood Insurance Program (NFIP), to reduce future flood damage. In fact, it takes in account the relative preventive effort of communities participating in NFIP by crediting points, according to the implemented actions that goes beyond the minimum NFIP requirements [45]. The score obtained by a community aims to reflect the reduced flood risk.

The assessment of points relative to each activity was developed through a first weighting forum in 1989, involving a wide range of stakeholders: (i) federal, state, and local officials, (ii) professionals with expertise in floodplain management, (iii) insurance industry and underwriting experts and (iv) academic researchers [45, 46]. As an already implemented and recognized work, the Community Rating System appears a structuring point of comparison regarding our own tool development.

The use of expert valuation raises the question of the relevance of the expert panel. Regarding the great diversity of actions implemented in PAPI, the constituted panel gathers:

-both transversal experts and specific experts regarding each six main lever of actions 
including experts in floodplain or hydraulic infrastructures management, dedicated national structures to education...

-representatives of the three main categories of stakeholders relative to FRM: (i) the State and its deconcentrated services at more local scales, (ii) territorial authorities including pilot structures of PAPI at the risk basin scale and (iii) civil society and prevention experts which covers insurance professionals, nongovernmental associations of flood-damaged people as well as private and public experts (public structures that are part of the technical and scientific Network of the French Ministry in charge of environment and academic researchers)...

The question that follows the choice of expert valuation is the method. How can we build a relevant and robust rating by using a qualitative approach?

\subsection{Selection of a multi-criteria analysis (MCA) method}

Actions' codes rating has to reflect their impact with regards to collective risk coping capacity and collective vulnerability reduction. With regards to the high diversity of codes and levers of action, several criteria have to be handled in order to assess them. With regards to our operational objective within our PPP framework, the two main criteria are the question of vulnerability reduction, considered as damaging propensity, and the collective dimension of the codes. Indeed, to what extent does the type of action have an impact on the entire risk basin or part of it?

To that end, MCA offers a great range of methods that are based on expert valuation [47, 48]. The two main MCA scholarships differ in their aggregation methods: the French scholarship is based on a partial synthesis of judgments through outranking while the American scholarship uses complete aggregation methods that end in a complete ordering of alternatives [47]. As we aim to rate all codes, only the American MCA methods can be used.

Within complete aggregation methods, AHP-ANP (Analytic Hierarchy Process and Analytic Network Process) developed by Pr. Saaty and the MAUT (MultiAttribute Utility Theory) are the most common methods [49]. Considering time consuming and practicability, we choose the AHP-ANP methods. They have several advantages: (i) it can be applied to varied situations (ii) simplicity (iii) only method to check judgment consistency (iv) ANP takes in account interdependencies between criteria and/or alternatives [47].

\subsection{The AHP-ANP model}

The use of AHP-ANP methods will consider two scales: (i) the comparison of the six mains levers of actions and (ii) the rating of each 82 codes' contribution to one or several lever of actions.
The first scale is based on an ANP model in order to take in account the interdependencies between the levers of actions. For example, building a dyke requires knowledge. But knowledge doesn't impact damaging propensity, because the effect is indirect. It depends on the knowledge's use towards concrete actions. In that sense, knowledge isn't credited points according to its impact but through the dependencies of the others levers on it. For this ANP model, the relative mode is used: weights reflect the relative importance of interdependencies, and pairwise comparisons of levers regarding each identified relevant criteria will determine relative weights of the levers. The criteria reflect the following questions: to what extent each lever impacts exposure? Sensitivity? In terms of reduction of damaging propensity? Of its non-aggravation? Are they sustainable?

The second scale relies on AHP models. The objective is to measure the contribution of the 82 codes for each lever of action (six subnets). Here, the rating mode is used so that the determined weight isn't dependent on the number of contributing codes. Thus, the rating consists in the attribution of an intensity degree to each code regarding the identified criteria. For example, experts will have to rate outreach projects' codes regarding the target: does it consider everybody on the territory, almost everybody or does it concern only a small part of the population? And give the relative weight of importance of the used intensities.

Finally, the two scales will allow giving a quantitative weight for each code of actions. The scoring of each PAPI and thus, of collective prevention, will result in the sum of the weights according to the actions it has implemented.

\section{Discussion and perspectives}

This research project, as many other projects, tackles with vulnerability assessment issues. In a specific PPP framework, between a urban planning lab and an insurance association, the current project aims to bridge the existing various conceptual frameworks related to vulnerability. Defined as the damaging propensity, we aim to assess one key factor at the collective scale: flood risk coping capacity. Thus, the current project proposes to address the question of vulnerability from action. It therefore joins the more general concern that emphasizes the recognition of territorial and societal capacity to move on from a fatalistic view towards prevention and more resilient territories.

Considering flood risk, public policy instruments stand for collective capacities and collective implemented actions. Throughout the existing instrument, we emphasize Action Programmes for Flood Prevention, as they address all the six main identified levers of actions. By constituting an action database, we identified 82 categories of actions through a codification process.

The upcoming experimentation of the codes' rating method thanks to expert valuation will provide several opportunities: (i) gathering and confronting different expert opinions regarding preventive measures, (ii) 
testing the methods' robustness through expert final feedback regarding weights and PAPI's scoring, (iii) testing robustness of a national rating system through case studies and their local specificities.

\section{References}

1. Scheuer, S., Haase, D., \& Meyer, V. (2011). Exploring multicriteria flood vulnerability by integrating economic, social and ecological dimensions of flood risk and coping capacity: from a starting point view towards an end point view of vulnerability. Natural Hazards, 58(2), 731-751.

2. Birkmann, J. (2006). Measuring vulnerability to promote disaster-resilient societies: Conceptual frameworks and definitions. Measuring vulnerability to natural hazards: Towards disaster resilient societies, 1, 9-54.

3. United Nations (2005). Hyogo Framework for Action 2005-2015: Building the Resilience of Nations and Communities to Disasters, World Conference on Disaster Reduction, 18-22 January 2005, Kobe, Hyogo

4. Fuchs, S., Birkmann, J., \& Glade, T. (2012). Vulnerability assessment in natural hazard and risk analysis: current approaches and future challenges. Natural Hazards, 1-7.

5. Reghezza, M. (2006). Réflexions autour de la vulnérabilité métropolitaine: la métropole parisienne face au risque de crue centennale, Thèse de doctorat, Université de Nanterre-Paris X.

6. Sansévérino-Godfrin V. (2008). Le Cadre juridique de la gestion des risque naturels. Paris : Éditions Tec \& Doc, Éditions Lavoisier, coll. «Sciences du risque et du danger $», 70 \mathrm{p}$.

7. Hewitt, K., (1983). Interpretation of Calamity from the Viewpoint of Human Ecology, Allen and Unwin, Londres, $304 \mathrm{p}$

8. White, G. F. (1974). Natural Hazards: Local, National, Global, Oxford University Press, Oxford, 288 p.

9. Fabiani, J.-L. et Theys, J. (1987). La société vulnérable : évaluer et maîtriser les risques, Presses de l'École normale supérieure, Paris, 674 p.

10. Thouret, J. C., \& D'ercole, R. (1996). Vulnérabilité aux risques naturels en milieu urbain: effets, facteurs et réponses sociales. Cahiers des sciences humaines. ORSTOM, 32(2), 407-422.

11. Ledoux, B. (2006). La gestion du risque inondation. Éditions Tec \& Doc.

12. De León, V., \& Carlos, J. (2006). Vulnerability: a conceptional and methodological review. UNU-EHS.

13. Barroca, B. (2006). Risque et vulnérabilités territoriales: Les inondations en milieu urbain, Doctoral dissertation, Université de Marne la Vallée, Génie urbain-aménagement de l'espace, urbanisme).

14. Brooks, N., 2003, « Vulnerability, Risk and Adaptation : A Conceptual Framework », http://www.cru.uea.ac.uk/ e118/publications/ Brooks-tynWP.pdf,
15. Gallopín, G. C. (2006). Linkages between vulnerability, resilience, and adaptive capacity. Global environmental change, 16(3), pp 293-303.

16. Gleyze, J. F. (2002). Introduction au risque. Rapport interne de 1 'IGN.

17. Léone, F. (2007). Caractérisation des vulnérabilités aux catastrophes naturelles: contribution à une évaluation géographique multirisque, HDR, université de Montpellier III, Montpellier, 2007.

18. Miller, F., Osbahr, H., Boyd, E., Thomalla, F., Bharawani, S., Ziervogel, G., ... \& Hinkel, J. (2010). Resilience and vulnerability: complementary or conflicting concepts?. Ecology and Society, 15(3).

19. Djament-Tran, G., Le Blanc, A., Lhomme, S., Reghezza-Zitt, M., \& Rufat, S. (2012). Ce que la résilience n'est pas, ce qu'on essaye de lui faire dire. Mars, hal-00679293, version, 1-15.

20. Smit, B., \& Wandel, J. (2006). Adaptation, adaptive capacity and vulnerability.Global environmental change, 16(3), 282-292.

21. Gérin, S. (2011). Méthodologie d'évaluation des PPRN dans le contexte de l'assurance des catastrophes naturelles, Thèse de doctorat, Université Paris 7 - Paris Diderot, UMR 8586 PRODIG

22. Nussbaum, R. (2015). Involving public private partnerships as building blocks for integrated natural catastrophes country risk management-Sharing on the French national experiences of economic instruments integrated with information and knowledge management tools. IDRiM Journal, 5(2), 82-100.

23. AFA (2015), Synthèse de l'étude changement climatique et assurance, Risques climatiques : quels impacts sur l'assurance contre les aléas naturels à l'horizon 2040 ?, 29p.

24. GIEC, 2014: Changements climatiques 2014: Rapport de synthèse. Contribution des Groupes de travail I, II et III au cinquième Rapport d'évaluation $\mathrm{du}$ Groupe d'experts intergouvernemental sur l'évolution du climat [Sous la direction de R.K. Pachauri et L.A. Meyer]. GIEC, Genève, Suisse, $161 \mathrm{p}$.

25. Field, C.B. (2012). Managing the risks of extreme events and disasters to advance climate change adaptation: special report of the intergovernmental panel on climate change. Cambridge University Press.

26. D’Ercole, R. et alii, 1994, « Les vulnérabilités des sociétés et des espaces urbanisés : concepts, typologie, modèles d'analyse ", Revue de Géographie Alpine, vol. 82, no 4, p. 87-96.

27. Steinführer, A., De Marchi, B., Kuhlicke, C., Scolobig, A., Tapsell, S., \& Tunstall, S. (2009). Vulnerability, resilience and social constructions of flood risk in exposed communities. FLOODsite report T11-07-12, http://www.floodsite.net.

28. André, C. (2013). Analyse des dommages liés aux submersions marines et évaluation des coûts induits 
aux habitations à partir de données d'assurance: perspectives apportées par les tempêtes Johanna (2008) et Xynthia (2010)(Doctoral dissertation, Université de Bretagne occidentale-Brest).

29. Bourguignon, D. (2014), Évènements et territoires Le coût des inondations en France, Analyse spatiotemporelle des dommages assurés, Thèse de doctorat, 310p.

30. Birkmann, J., \& Wisner, B. (2006). «Measuring the unmeasurable. The challenge of vulnerability. » UNUEHS Source, 5.

31. Kasperson, R.E., Dow, K., Archer, E., Caceres, D., Downing, T.,Elmqvist, T., Eriksen, S., Folke, C., Han, G., Iyengar, K., Vogel, C., Wilson, K., Ziervogel, G., 2005. Vulnerable people and places. In:Hassan, R., Scholes, R., Ash, N. (Eds.), Ecosystems and Human Wellbeing:Current State and Trends, vol. 1. Island Press, Washington, DC,pp. 143-164.

32. Turner, B. L., Kasperson, R. E., Matson, P. A., McCarthy, J. J., Corell, R. W., Christensen, L., ... \& Polsky, C. (2003). A framework for vulnerability analysis in sustainability science. Proceedings of the national academy of sciences, 100(14), 8074-8079.

33. Chemitte , J. (2008), Adoption des technologies de l'information géographique et gestion des connaissances dans les organisations. Application à l'industrie de l'assurance pour la gestion des risques naturels, Doctoral dissertation, 260p.

34. Cardona, O. D. (2004). «The need for rethinking the concepts of vulnerability and risk from a holistic perspective: a necessary review and criticism for effective risk management. ", Mapping vulnerability: Disasters, development and people, 37-51.

35. UN/ISDR -International Strategy for Disaster Reduction- (2002): Living with Risk: A Global Review of Disaster Reduction Initiatives, Geneva: UN Publications.

36. Ashley, R., Blanksby, J., Maguire, T., \& Leahy, T. (2010). Frameworks for adapting to flood risk: experiences from the $\mathrm{EU}^{\mathrm{ee}} \mathrm{s}$ flood resilient city project, International Association for HydroEnvironment Engineering and Research (IAHR).

37. Hegger, D. L. T., Green, C., Driessen, P. P. J., Bakker, M. H., Dieperink, C., Crabbé, A., ... \& Fournier, M. (2013). Flood Risk Management in Europe: Similarities and Differences between the STAR-FLOOD consortium countries.

38. Steinführer, A. (2009). Local communities at risk from flooding: social vulnerability, resilience and recommendations for flood risk management in Europe. Helmholtz-Zentrum für Umweltforschung, Department Stadt-und Umweltsoziologie.

39. Larrue, C., Bruzzone, S., Lévy, L., Gralepois, M., Schellenberger, T., Trémorin, J.B., Fournier, M., Manson, C., Thuilier, T, (2015.) Analysing and evaluating Flood Risk Governance in France: from State Policy to Local Strategies T, French STARFLOOD Team, Tours, France.

40. Dourlens, C. (2003). La question des inondations : le prisme des sciences sociales. Rapport au Ministère de l'équipement, des Transports et du Logement (DRAST)

41. Mény, Y., Thoenig, J.C. (1989) Politiques publiques. Collection Thémis Science Politique PUF, 391 p.

42. Huitema, D., E. Mostert, W. Egas, S. Moellenkamp, C. Pahl-Wostl, and R. Yalcin. 2009. Adaptive water governance: assessing the institutional prescriptions of adaptive (co-)management from a governance perspective and defining a research agenda. Ecology and Society 14(1): 26.

43. Charry, J. C., \& Ministère de l'Aménagement du Territoire et de l'Environnement France. (1997). Plans de prévention des risques naturels prévisibles (PPR): Guide général. La Documentation Francaise.

44. Grelot, F. (2004), Gestion collective des inondations, peut-on tenir compte de l'avis de la population dans la phase d'évaluation économique a priori, Doctoral dissertation, 391p.

45. FEMA-Federal Emergency Management Agency(2015). National Flood Insurance Program Community Rating System: 2014 Biennial Report to Congress $24 \mathrm{pp}$.

46. NFIP - National Flood Insurance Program, (1989). Report on the Activity Weighting Forum. 23 pp.

47. Renard, F. (2010). Le risque pluvial en milieu urbain: de la caractérisation de l'aléa à l'évaluation de la vulnérabilité: le cas du Grand Lyon, Thèse de doctorat, Lyon 3

48. Saaty, T. L., \& Ergu, D. (2015). When is a DecisionMaking Method Trustworthy? Criteria for Evaluating Multi-Criteria Decision-Making Methods. International Journal of Information Technology \& Decision Making, 1-17.

49. Huang, I. B., Keisler, J., \& Linkov, I. (2011). Multicriteria decision analysis in environmental sciences: ten years of applications and trends. Science of the total environment, 409(19), 3578-3594. 